\title{
A Design and Development of Prototype Web Based Tourism Information System (WBTIS) for the Maharashtra and Goa States of India
}

\author{
K.B. Mahajan \\ Department of Physics, MooljiJaitha College, Jalgaon, \\ MS, India \\ E-mail: kbmahajan@gmail.com
}

\author{
A.S. Patil
}

School of Computer Sciences, North Maharashtra University, Jalgaon, MS, India

E-mail: aspatil@nmu.ac.in

\author{
R.R. Attarde \\ Department of Physics, MooljiJaitha College, Jalgaon, \\ MS, India \\ E-mail: rrattarde@gmail.com
}

\author{
R.H. Gupta \\ Sant Muktabai Arts and Commerce College, \\ Muktainagar, Dist. Jalgaon, MS, India \\ E-mail: gupta-raj07@yahoo.co.in
}

\author{
B. V. Pawar \\ School of Computer Sciences, \\ North Maharashtra University, Jalgaon, MS, India \\ E-mail: bvpawar@nmu.ac.in
}

\begin{abstract}
Travelling for the purpose of recreation is termed as Tourism. It is an industry to move, house and entertain people.The tourism industry is dynamic and competitive and is amongst the world's largest service provider industries. It is also one of the fastest growing economic sectors in terms of generating gross revenueas well as earning of foreign exchange. The Internet and the developments in ICTs is a perfect platform for the tourism industry to bring its products and servicesdirectly to the customers. The Internet provides several tools like Google maps, GPS, interactive communication, email, payment gateways etc to create a new business environment. In order to increase the effectiveness and efficiency of different types of transactions, by reducing their cost and to provide one stop services to the customers, we propose a new Web-Based Tourist Information System (WBTIS) for Maharashtra and Goa states of India, which consists of all the information channels used in a business or community to promote itself as a tourism attraction.
\end{abstract}

Keywords-tourism; maharashtra; goa; information communication tools; wbtis

\section{INTRODUCTION}

Today, travel and tourism is one of the world's largest service provider industries and one of the world's fastest growing economic sectors. Tourist arrivals worldwide grew at an average rate of 4.3 percent per annum. According to the World Travel and Tourism Council, travelandtourism represent approximately $11 \%$ of the worldwide GDP. World Tourism Organization has predicted one billion international arrivals in the year 2010 and has forecasted that by 2020, international tourist arrivals to Asia and Pacific region would experience over 400 percent growth from 105 million in 2000 to 438 million in 2020 [1].
The importance of tourism lies in the sense that after busy and tense work schedule in this competitive world, everybody wants to go for tour and expects that it would bring pleasant memories and leisure. In order to make the tours pleasant, they should be able to plan the tours in advance, select of the spots of tourism, book tickets for traveling, getting knowledge about local transportations and accommodations and to decide what to and how to purchase during tours. In $21^{\text {st }}$ century IT has entered into all aspects of human life nothing is exception to tourism. The Internet and the developments in information and communication technologies (ICTs) have revolutionized the entire tourism industry, generating new business models, changing the structure of the tourism distribution channels and reengineering all traditional tourism processes. ICTs have been transforming the traditional process of all tourism activities. This means, throughout the world ICTs have been transforming tourism. With the help of ICT and WWW it is possible to provide various services mentioned above to the tourists. The Internet and other communication technologies for tourism promotion can alter the structure of tourism industry, as tourism plays significant role in the economy of any country/state. The present work is aimed to explore the impact of ICTs and the Internet in particular in the tourism industry of Maharashtra and Goa states of India.

The new Web Based Tourism Information System we have proposed and presented helps in bringing the products and other services online on the web for easy and anytime remote access to tourists. WBTIS is an information platform designed especially to fulfillthe needs of tourists consistall the information abouttourism in Maharashtra and Goa states of India and will be a guide for all kinds of tourists to locate the information they are looking for. The main purpose of the system is to provide complete tourism 
information through the internet and at the same time it helps to contribute to the increase in business and growth of the tourism industry in the states of Maharashtra and Goa. This WBTIS can be a promising way to promote tourism in the states of Maharashtra and Goa.

\section{LITERATURE REVIEW}

The Internet is more and more emerging as a handy tool of travel agents forthe tourism industry. It represents a perfect platform to bring products andservices to the customer in a direct way without using traditionalintermediaries. However, the Internet (web) based tourist information system do not provide just brochures online, they also provide value and service. One of the firstweb based tourist information system is TIScover [2]. [3] studies needs of users, details the use of interactive tourism maps to present tourism as an object in geographic context, support for tourism planning, It also highlights analysis, decision making and management using Geographical Information System (GIS) techniques and showing the results on the internet. [4] discusses the hybridapproach on the concept used for pre-generation of web pages. In [5]the author discusses the design goals of Web-based Tourist InformationSystem. [6] introduces a general data model for tourist informationsystem and discusses the transformation process and shows that it can also beused as a generic data model for new applications. [5] is dedicated tothe concepts and mechanisms used for the maintenance of huge touristinformation base making special emphasis on the customization of tourismproducts. [7] discusess the the holiday package facility of TIScover. TIScover is the largest Webbased tourism information system in Austria. [8] mentions WETIS (Web based tourist information system) portal for East Slovakia which has an interactive GUI (graphical user interface). The GUI provides search facility to look for objects and allows creation of own objects. [9] discusses the issues regarding the designing of web based tourism center.[10] discusses the use of Information Technology in Tourism . Mahajan et.al [11] surveyed 250 tour operators, travel agencies, hotels etc., to calculate the use of ICT by the Maharashtra and Goa tourism industry. They also proposed [12] a new ICT based tourism business model that includes modern ICT tools which directly impacts the tourism business.

\section{OBJECTIVES}

The objectives of the design of the WBTIS are:

- To make optimal and appropriate use of web friendly ICT tools for promotion of tourism of both the states

- To attract tourists to Maharashtra and Goa, thus helping the state's tourism industry to grow

- To establish linkage between different actors of the tourism industry

- To provide a quick, reliable and accurate tourism related information

- To provide appropriate navigation and search mechanisms to locate the desired information in a convenient and efficient manner.

\section{SCOPE OF WBTIS}

The scope of WBTIS is spread over to the different user groups differentiated by the system into three major components like tourists (travelers), information providers (tourism related) like tour operators, travel agents, hoteliers, attraction owners etc., and administrator of the system (see fig.1). WBTIS is a system specially designed and aimed towards tourists/travelers, tour operators, travel agents, hoteliers and attraction owners. The main purpose of WBTIS is to provide reliable, accurate, interesting and upto-date information on Maharashtra and Goa states and to promote tourism in these states through the internet. WBTIS also acts as a perfect medium for various actors and tourism business partners to promote their products and services globally.

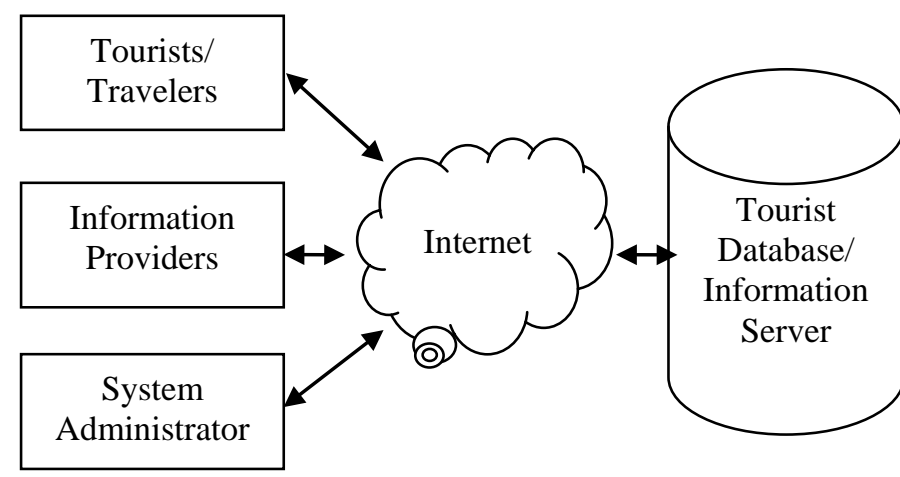

Figure1. Functional Components of WBTIS.

\section{DESIGN OF THE SYSTEM}

During the analysis phase, it's important to identify the non-functional and functional requirements. In functional requirement an interaction between the system and its environment is described. There are three main modules have been identified in these functional requirements that are as follows:

- Tourists/Travelers

- Information providers and

- System administrator

\section{A. Tourists/Travelers}

The tourists/travelers are the internet users who wish to find information on holiday destinations in Maharashtra and Goa and other relevant tourism information. The scope of this component covers following modules which are developed to satisfy the needs of the tourists.

- General information about Maharashtra and Goa states

- Tourist places/holiday destinations in

- Maharashtra and Goa

- Promotional offers

- Holiday packages

- Calendar of events in Maharashtra and Goa states

- Links to various web pages

- Tourist registration

- Search module 


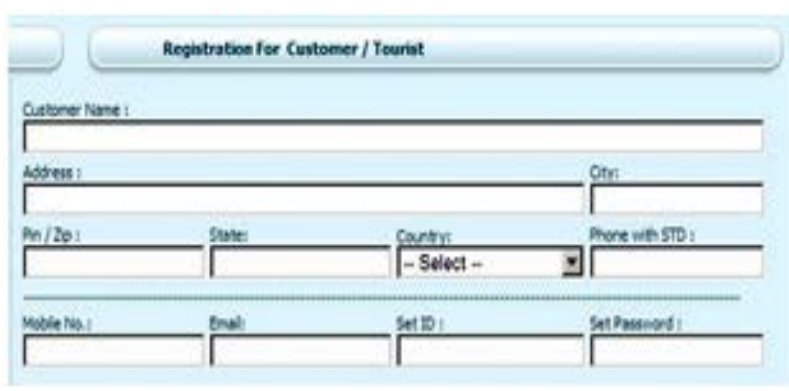

Figure 2. Webpage shows the Registration Form for Tourist/Traveler.
The names of the modules are self explanatory and the name stands for the purpose of the module. The search module allows two types of interface to locate the desired information. The tourist is provided with an interface where he can collect tourism data by browsing and clicking maps based on geographical hierarchy. The geographical hierarchy starts from India then Maharashtra followed by districts, talukas and finally the tourist destination. Fig. 3 shows a sample webpage that depicts the hierarchy wise searching of destinations ranging from state, region and district to city/village/destination

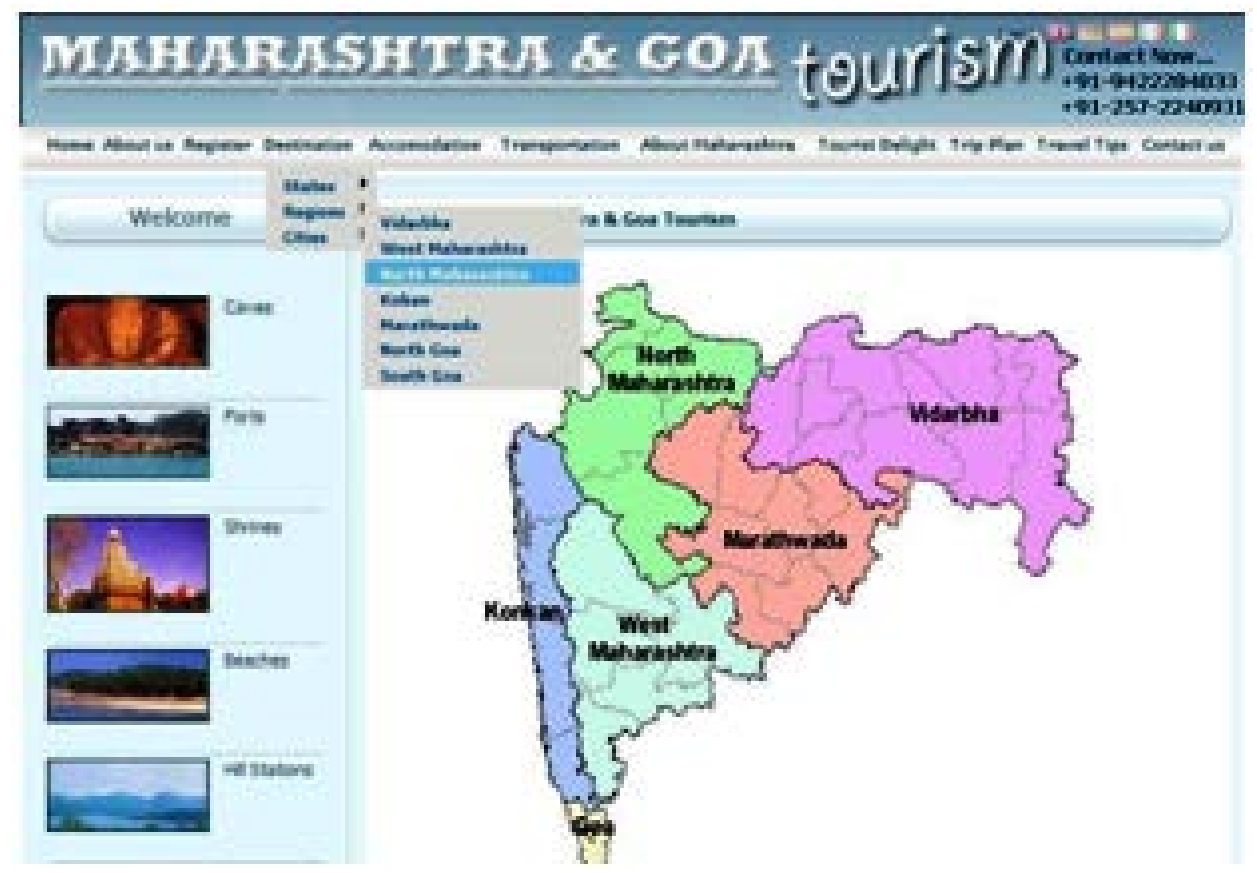

Figure 3. Webpage shows the Hierarchy wise Searching of Destinations Ranging from State, Region and District to City/Village/Destination.

The second type of interface allows the information seeker to directly search information related to time tables, hotel bookings, tourist destinations, events etc. The tourist can register himself so that he can receive regular updates from the system via email or SMS. He can also use various other services of the system like planning of a trip etc.

\section{B. Information Providers}

The information providers consists of tour operators, travel agents, hoteliers and attraction owners that provide information related to Maharashtra and Goa tourism.

These companies will promote their business (packages) through the system and simultaneously, making such information available to the general user of the system. This module is only accessible with proper authorization from all tourism information providers that are the partners of WBTIS. The major functionality of this module is represented by the maintenance module and the booking reports module.

This component covers the following modules:

- Registration module

- $\quad$ Login module
- $\quad$ Add information module

- Delete information module

- Information maintenance module

The registration module is a very important module of the system. Figure 4 shows a sample webpage that depicts the online registration form for tourism business partners. The information is filled online and a hardcopy (generated by the system) along with necessary documents is to be submitted to the system administrator. The administrator later verifies this information and allows the registration of the actor to the system. The actor then can login to the system with an automatic password generated by the system, which is sent to the actor through email. For the purpose of login the user will use the login module. Add, delete and information maintenance modules are used to add, remove and update various kinds of information related to the actors business. 


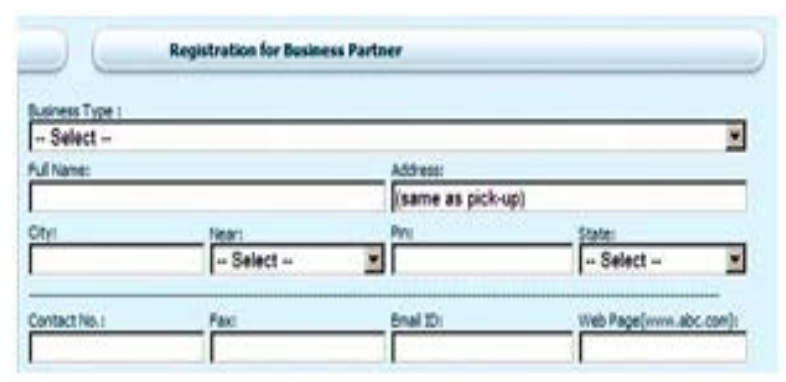

Figure 4 Webpage shows registration form for tourism business partners.

\section{System Administrator}

Finally system provider module of WBTIS is only accessible by system administrator. Figure 5 shows a sample webpage that depicts the system administrator login.

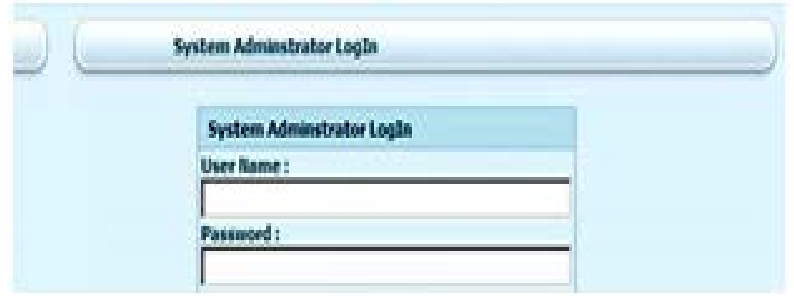

Figure 5. Webpage shows system administrator login.

The system provider is responsible for the configuration of the whole system and making it available for the public or tourists. He is also responsible in maintaining the system and ensures its efficiency. This component covers the following modules:

- Administrator login

- Add information

- Delete information

- Information Maintenance

\section{OTHER REQUIREMENTS FROM WBTIS}

Apart from the functional requirements discussed in the previous sections it is necessary for the system to satisfy other non functional requirements. It includes various requirements like security, reliability, usability, scalability and timely availability of information. During the design of WBTIS utmost care has been taken to satisfy the above requirements. Document verification after registration of the actors, password based authentication, hosting of information on state of the art hosting facility etc. make it possible to satisfy the non functional requirements.

\section{CONCLUSION}

WBTIS provides online and up to date information about Maharashtra and Goa states WBTIS acts as an intermediary between tour operators, travel agents, hoteliers, attraction owners and local or foreign tourists. The WBTIS builds a virtual community of users, integrates the processes or functions of tourism business and establish linkages among the players within the tourism industry and across various industries related to the tourism industry. The
WBTIS is also an important tool that easily copes with the information change.

\section{REFERENCES}

[1] E. Duran, D. Z. Seker, M. Shrestha, "Web Based Information System For Tourism Resorts: A Case Study For Side/Manavgat”, in the Proceedings of the Youth Forum, ISPRS 2004 Congress Istanbul, pp.90,12-23 July 2004.

[2] Vivek Gupta, Devashish Das Gupta, “Adoption and Use of ICT in Indian Tourism: Interventions for the top tourist destinations of India”, in the conference on tourism in India - Challenges Ahead, 1517 May 2008.

[3] Norjihan Abdul Ghani, Syahranah Ahmad Raqi, "Designing a WebBased Tourism Information Center", SITMA 2005, Terengganu, Malaysia, 19-20 August 2005.

[4] J. Kung, A. Dunzendorfer, R. R. Wagner, "A General Data model for Tourism Information Systems", in the Proceedings of the International Conference on Information and Communication Technologies in Tourism, (ENTER 1999), Innsbruck, Austria, pp. 151-160, 1999. 
[5] B. Proll, W. Retschitzegger, H. Sighart, H. Strack, "Ready for Prime Time - Pre-Generation of Web Pages in TIScover", in proceeding of the 8th International ACM conference on Information and Knowledge Management (CIKM), Kansas city, Missouri November 1999.

[6] B. Proll, W. Retschitzegger, R. R. Wagner, A. Ebner, Beyond "Traditional Tourism Information System- The Web-Based Approach TIScover", in the Journal of Information Technology \& Tourism, Applications, Methodologies, Techniques, Hannes Werthner (Ed.), pp. 15-31, ISSN 1098-3058, Cognizant Communication Corporation, Vol. 1, Inaugural Volume, New York Sydney - Tokyo, 1998.

[7] B. Proll, W. Retschitzegger, R. R. Wagner, "Holiday Packages on the Web", in the proceeding of the International Conference on Technologies for Tourism (ENTER), Springer, Innsbruck, 1999.

[8] B. Proll, W. Retschitzegger, R. R. Wagner, “TIScover-A Web-based Tourist Information System", in the proceeding of the EURO-MED NET 98 Conference, Nicosia, Cyprus, pp. 93-94, March 1998.

[9] Gejza M. Timcak, Heinz Schleusener, Jana Jablonska, "WETIS - A Web Based Tourist Information System for East Slovakia" , in ActaMontanisticaSlovacaRocnik ISSN 1335-1788, Vol. 14, Issue. 3, pp. 205-212, 2009.

[10] K.B.Mahajan, B.V.Pawar, "On the Use of Information Technology in Tourism", Library progress (International) ISSN. 0970 -1052, Vol. 21 No.1-2, 2001, P.P. 25-28.

[11] K.B. Mahajan, A. S. Patil, R. H. Gupta, B.V. Pawar, "Use of Information and Communication Technology in the Tourism Industry of Maharashtra and Goa States: A Survey", International Journal of Hospitality and Tourism System (IJHTS), Volume 4 Issue 2, pp. 6169. ISSN: 0947-6250, Dec. 2011.

[12] K. B. Mahajan, A. S. Patil, R. H. Gupta, B. V. Pawar, "A New ICT based Business Model for Tourism Industry for the Maharashtra and Goa States of India” International Journal of Hospitality \& Tourism Systems (IJHTS), Volume 8 Issue 1, pp 64-69 ISSN: 0947-6250 Print, June 2015 